Jpn. J. Genet. (1986) 61, pp. 361-370

\title{
Spontaneous reciprocal translocations in cultivated form of Emmer wheat ${ }^{1)}$
}

\author{
By Kozo Nishikawa, Akira Takagi, Tomohiro BAN, Hiroaki Otsuka \\ and Yoshihiko Furuta \\ Faculty of Agriculture, Gifu University, 1-1 Yanagido, Gifu 501-11
}

(Received June 18, 1986)

\begin{abstract}
Twenty-one $\mathrm{F}_{1}$ hybrids among fourteen varieties or cultivars of cultivated form of Emmer wheat were studied with respect to chromosome pairing at MI of PMC's, and four chromosome types were determined according to the reciprocal translocations detected.

In relation to LD 222 type that was recognized as a standard, Ethiopicum type had a reciprocal translocation between $2 \mathrm{~A}$ and $4 \mathrm{~A}$, and two translocations among three chromosomes, i.e. $4 \mathrm{~A}-2 \mathrm{~A}: 2 \mathrm{~A}-2 \mathrm{~B}$, were carried by Abyssinicum type. Liguliforme type had two different translocations, the one being between $7 \mathrm{~A}$ and $5 \mathrm{~B}$, but the other unidentified.
\end{abstract}

\section{INTRODUCTION}

Reciprocal translocation or segmental interchange of chromosomes can be detected by a ring or a chain of chromosomes formed at the first meiotic metaphase in the heterozygote. There are a lot of spontaneous reciprocal translocations found in various plant species (Burnham 1956). Oenothera and Rhoeo are widely known because of the ring linking up all the chromosomes in the translocation heterozygote.

Reciprocal translocation may serve as a tool for cytogenetical researches. The artificially induced reciprocal translocations have been investigated most intensively in maize and followed by barley, rice and some others. In wheat Yamashita (1950) studied the induced reciprocal translocations in diploid wheat and succeeded in linking all fourteen chromosomes in a ring in the heterozygote for six different reciprocal translocations. Some earlier instances of the reciprocal translocation in Emmer wheat were reported by Hosono (1935), Smith (1947), Nishikawa (1962) and Dalal and Sadanaga (1965). Kawahara and Tanaka (1978) and Kawahara (1984) studied intraspecific structural differentiation of chromosomes, especially reciprocal translocations in wild tetraploid wheats. In hexaploid wheat, more studies have been reported (cf. Kawahara 1984).

1) Contribution from the Laboratory of Genetics and Plant Breeding, Faculty of Agriculture, Gifu University, No. 70. The work was supported in part by a Grant-in-Aid for Co-operative Research (No. 56360001) from the Ministry of Education, Science and Culture, Japan. 
It is of a great importance to identify chromosomes involved in the reciprocal translocation, and it is desirable, if possible, to determine the break points. Among studies in wheat there are several reports, in which the monosomic series of common wheat has been used for identifying chromosomes involved in reciprocal translocations (cf. Kawahara 1984). Dalal and Sadanaga (1965) identified chromosomes $2 \mathrm{~A}(\mathrm{II})$ and 3A involved in a reciprocal translocation in T. carthlicum by use of Chinese Spring monosomics. Telocentric chromosomes may be useful as the markers, Linde-Laursen and Larsen (1974) used doublemonotelodisomics to identify translocations in common wheat.

In this paper reported are four chromosome types found in cultivated Emmer wheat and identification of the chromosomes involved in the translocations.

\section{MATERIALS AND METHODS}

Following fourteen varieties or cultivars were used, which all belong to Triticum turgidum (L.) THeLl.;

ssp. dicoccum (SchraNK) THELL. var. liguliforme, var. aureum, cv. Khapli, cv. Vernal

ssp. georgicum (DEK. et MEN.) MK var. georgicum

ssp. turgidum conv. durum (DESF.) MK var. reichenbachii, var. melanopus, var. africanum, var. ethiopicum, var. abyssinicum, var. pyramidale, cv. LD 222, sphaerococcum type mutant*

cov. polonicum (L.) MK var. gracile

Among these varieties or cultivars, twenty-one $F_{1}$ 's were raised and studied with respect to chromosome pairing at the first meiotic metaphase. Acetocarmine squash method was applied to PMC's fixed with Farmer's fluid.

\section{RESULTS}

\section{Four chromosome types detected in cultivated Emmer wheat}

Twenty-one different hybrids represented in Table 1 were studied with respect to chromosome pairing at MI of PMC's. In those hybrids involving LD 222 as one of parents and Vernal, reichenbachii, sp type mutant or polonicum as the other, complete pairing of 14 bivalents was observed in almost all PMC's. It was the same with the hybrid between Vernal and georgicum. There was, in addition to 13 bivalents, one trivalent having two telocentrics, one associated with either end of a complete chromosome in 96\% of PMC's in LD $222 \times$ melanopus hybrid. These observations clearly indicate that LD

*Schmidt and Johnson (1963). 
Table 1. Chromosome pairing at MI of PMC's in twenty-one different hybrids in cultivated form of Emmer wheat

\begin{tabular}{|c|c|c|c|}
\hline \multicolumn{2}{|c|}{ Cross combination } & Pairing type & Frequency (\%) \\
\hline \multicolumn{2}{|c|}{ LD $222 \times$ Vernal } & $14 "$ & 84.5 \\
\hline \multicolumn{2}{|c|}{$" \quad \times$ reichenbachii } & $14 "$ & 100.0 \\
\hline \multicolumn{2}{|c|}{$" \quad \times$ polonicum } & $14 "$ & 98.6 \\
\hline \multicolumn{2}{|c|}{$" \times s p$ like mutant } & $14 "$ & 90.3 \\
\hline \multicolumn{2}{|c|}{$" \times$ melanopus } & $(t+t) 1^{\prime \prime \prime}+13^{\prime \prime}$ & 96.0 \\
\hline \multicolumn{2}{|c|}{ Vernal $\times$ georgicum } & $14 "$ & 100.0 \\
\hline \multicolumn{2}{|c|}{ liguliforme $\times$ aureum } & $14 "$ & 90.4 \\
\hline \multicolumn{2}{|c|}{ ethiopicum $\times$ LD 222} & $1 ", '+12 "$ & 95.7 \\
\hline " & $\times$ africanum & $1 ", '+12 "$ & 77.5 \\
\hline " & $\times a b y s s i n i c u m$ & $1 ", '+12 "$ & 98.4 \\
\hline \multicolumn{2}{|c|}{ liguliforme $\times$ LD 222} & $1 ", '+12 "$ & $100.0^{*}$ \\
\hline & $\times$ georgicum & $1 ", "+12 "$ & $100.0^{*}$ \\
\hline \multirow{2}{*}{\multicolumn{2}{|c|}{ aureum $\times \mathrm{LD} 222$}} & $1 ", '+12 "$ & 63.8 \\
\hline & & $2, " '+10 "$ & 29.5 \\
\hline \multirow{2}{*}{\multicolumn{2}{|c|}{ melanopus $\times$ liguliforme }} & $(\mathrm{t}+\mathrm{t}) 3^{\prime \prime \prime \prime}+12$ ' & 76.1 \\
\hline & & $(t+t) 3^{\prime \prime \prime \prime}+1, " '+10^{\prime \prime}$ & 17.4 \\
\hline \multicolumn{2}{|c|}{ abyssinicum $\times$ LD 222} & $1,,, ",+11 "$, & 71.4 \\
\hline & $\times$ Khapli & $1 ",, ",+11^{\prime \prime}$ & 75.7 \\
\hline , & $\times$ pyramidale & 1 ",',' +11" & 100.0 \\
\hline , & $\times$ georgicum & $1 ", ", '+11^{\prime \prime}$ & $100.0^{*}$ \\
\hline , & $\times$ melanopus & $1, ", " \prime+(t+t) 1, "+10^{\prime \prime}$ & 76.4 \\
\hline , & $\times$ liguliforme & $1, ", ',+1, ",+9$, & 90.0 \\
\hline , & ×aureum & $1, ", ",+1, ",+9 "$ & 79.5 \\
\hline
\end{tabular}

* Only a few PMC's checked.

222 and others involved in these hybrids carry the same chromosome type. There was one more hybrid between liguliforme and aureum that formed 14 bivalents in $90.4 \%$ of PMC's with a few exceptions having a quadrivalent.

Three hybrids having ethiopicum as a female parent formed 1"' +12 " in most of PMC's. The same pairing was confirmed in the respective hybrids of liguliforme pollinated with either LD 222 and georgicum. While in the hybrid between aureum and LD 222 two quadrivalents were observed in about $30 \%$ of PMC's in addition to those $(63.8 \%)$ of 1 "' +12 " that was observed in $\mathrm{F}_{1}$ (liguliforme $\times \mathrm{LD} 222$ ). The hybrid between melanopus and liguliforme formed a quinquevalent marked with two telocentrics, one associated with either end of a chain of three complete chromosomes. This indicates that chromosome 5B takes part in a translocation of Liguliforme type, because melanopus carries 15 pairs of chromosomes (Tsunewaki 1963), of which two pairs are known to be the long and short arm telocentrics of chromosome 5B 


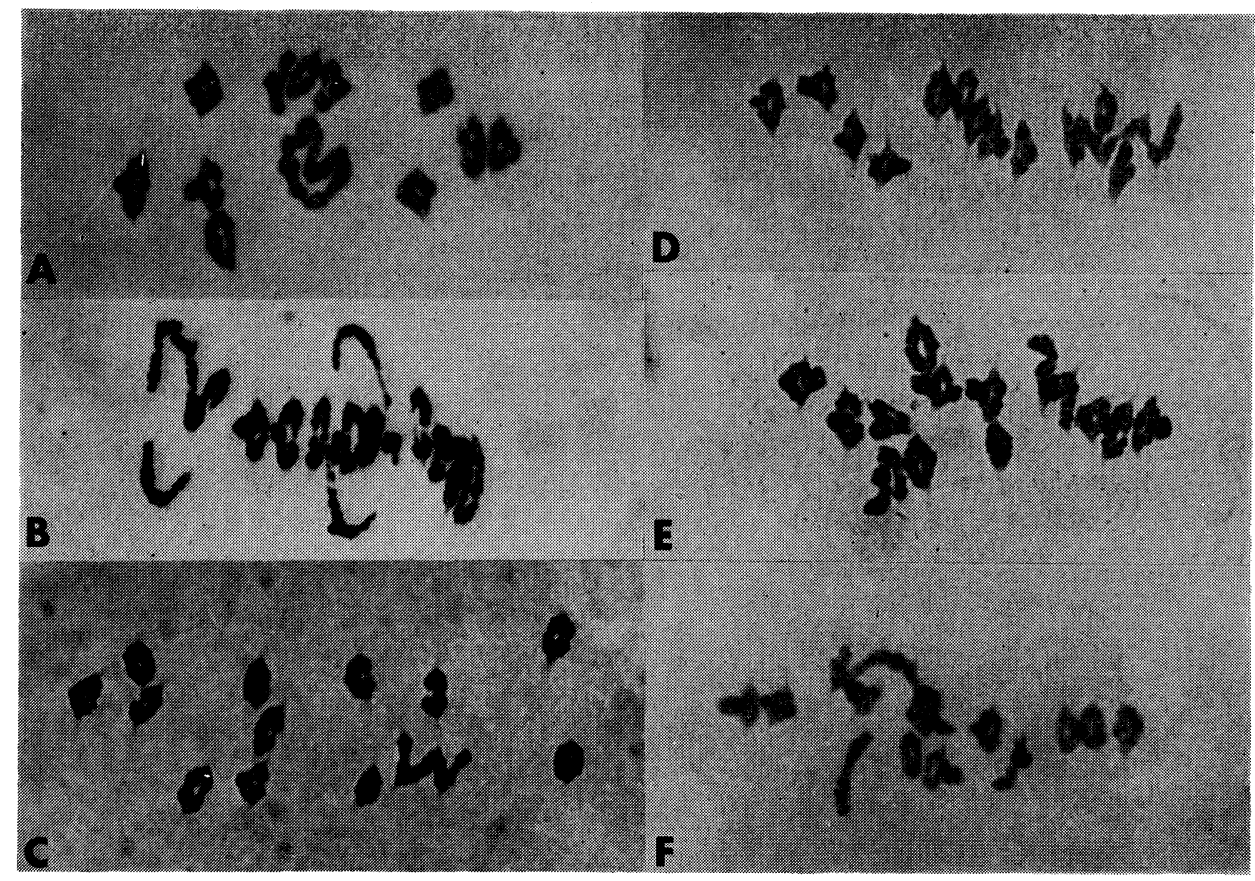

Fig. 1. Microphotographs showing chromosome pairing in PMC's. A: abyssinicum $\times$

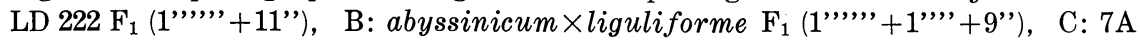
telocentric $\mathrm{F}_{1}$ of liguliforme $\left((\mathrm{t}+\mathrm{t}) 3^{\prime \prime}, ",+12\right.$ '), $\mathrm{D}-\mathrm{F}$ : abyssinicum $\mathrm{F}_{1}$ telocentric for

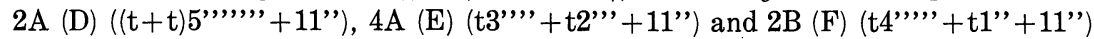

(Nishikawa unpublished). Furthermore, it formed another chain of four in some $20 \%$ of PMC's in addition.

Seven abyssinicum hybrids formed a sexivalent (Fig. 1-A) in at least 70\% of PMC's. In the rest the sexivalent dissociated to form two trivalents, one quadrivalent and one bivalent or one quinquevalent and one univalent. It is evident from these observations that there are two translocations involving three chromosomes that differentiate abyssinicum from others. 5B telocentrics from melanopus formed a heteromorphic trivalet. Two abyssinicum hybrids with either liguliforme and aureum formed a quadrivalent in addition to a sexivalent (Fig. 1-B) in almost all PMC's checked.

Summarizing the pairing behavior shown in Table 1, four chromosome types can be distinguished (Table 2). LD 222 type seems to be primitive (Nishikawa 1967) and is the most prevalent as evident in this study. So it is reasonable to assume that $\mathrm{LD} 222$ type is a standard type. Ethiopicum type on one hand and liguliforme and aureum on the other, though different from LD 222 type by one reciprocal translocation, showed different pairing behavior to abyssinicum. Then, it is considered that ethiopicum has the reciprocal translocation common to one of the two detected in abyssinicum, 
Table 2. Four chromosome types deduced from pairing analysis in the hybrids of cultivated form of Emmer wheat

\begin{tabular}{lccc}
\hline \multicolumn{1}{c}{ LD 222 type } & Ethiopicum type & Abyssinicum type & Liguliforme type \\
\hline LD 222, Vernal, & ethiopicum & abyssinicum & liguliforme \\
Khapli, georgicum, & & aureum \\
reichenbachii, & & \\
africanum, melanopus, & & \\
sp like mutant, \\
pyramidale, polonicum
\end{tabular}

while liguliforme and aureum have one reciprocal translocation different from those of abyssinicum. Further, liguliforme and aureum, though formed a rare quadrivalent in their hybrid, seem to be very similar, if not completely the same, in the chromo some type.

2. Identification of chromosomes involved in the reciprocal translocations

The hybrids telosomic or monosomic for the respective chromosomes were raised. These hybrids are denoted as $1 \mathrm{~A}$ through $7 \mathrm{~B}$ in Table 3 according to the chromosome in such condition.

a) Ethiopicum type

Chromosome pairing observed in the hybrids of LD 222 telosomic lines with ethiopicum is represented in Table 3. Lines $1 \mathrm{~A}, 3 \mathrm{~A}$ and $5 \mathrm{~A}$ through $7 \mathrm{~B}$, which were doubletelotrisomic showed pairing type 1 "" $+(t+t) 1$ " +11 " in most of PMC's checked. These lines are non-critical. One trivalent and one univalent, instead of a quadrivalent, were formed in some of these lines, especially in $7 \mathrm{~A}$ in about $20 \%$ of PMC's. One telocentric chromosome, probably of short arm, occasionally failed to associate with its homologue and resulted in a heteromorphic bivalent and a univalent in lines $1 \mathrm{~A}, 5 \mathrm{~A}, 6 \mathrm{~A}, 2 \mathrm{~B}$ and $4 \mathrm{~B}$. Line $2 \mathrm{~A}$ was monotelodisomic, having the long arm telocentric of chromosome $2 \mathrm{~A}$. It formed a heteromorphic quadrivalent with the telocentric associated with one end of a chain of three complete chromosomes in 70\% of PMC's. The remaining PMC's had a telocentric univalent and a chain of three completes. Line 4A, which was doubletelotrisomic, formed a quinquevalent marked with two telocentrics in $81 \%$ of PMC's. One or two telocentrics were rarely dissociated from the quinquevalent as univalents. From these observations, it is quite evident that lines $2 \mathrm{~A}$ and $4 \mathrm{~A}$ are the critical lines and Ethiopicum type of reciprocal translocation is between chromosomes $2 \mathrm{~A}$ and $4 \mathrm{~A}$.

b) Abyssinicum type

Two series of aneupoid hybrid lines were raised; one is a series involving LD 222 telosomic lines and the other Chinese Spring monosomic lines. In telosomic hybrid lines which were doubletelotrisomic, non-critical pairing 


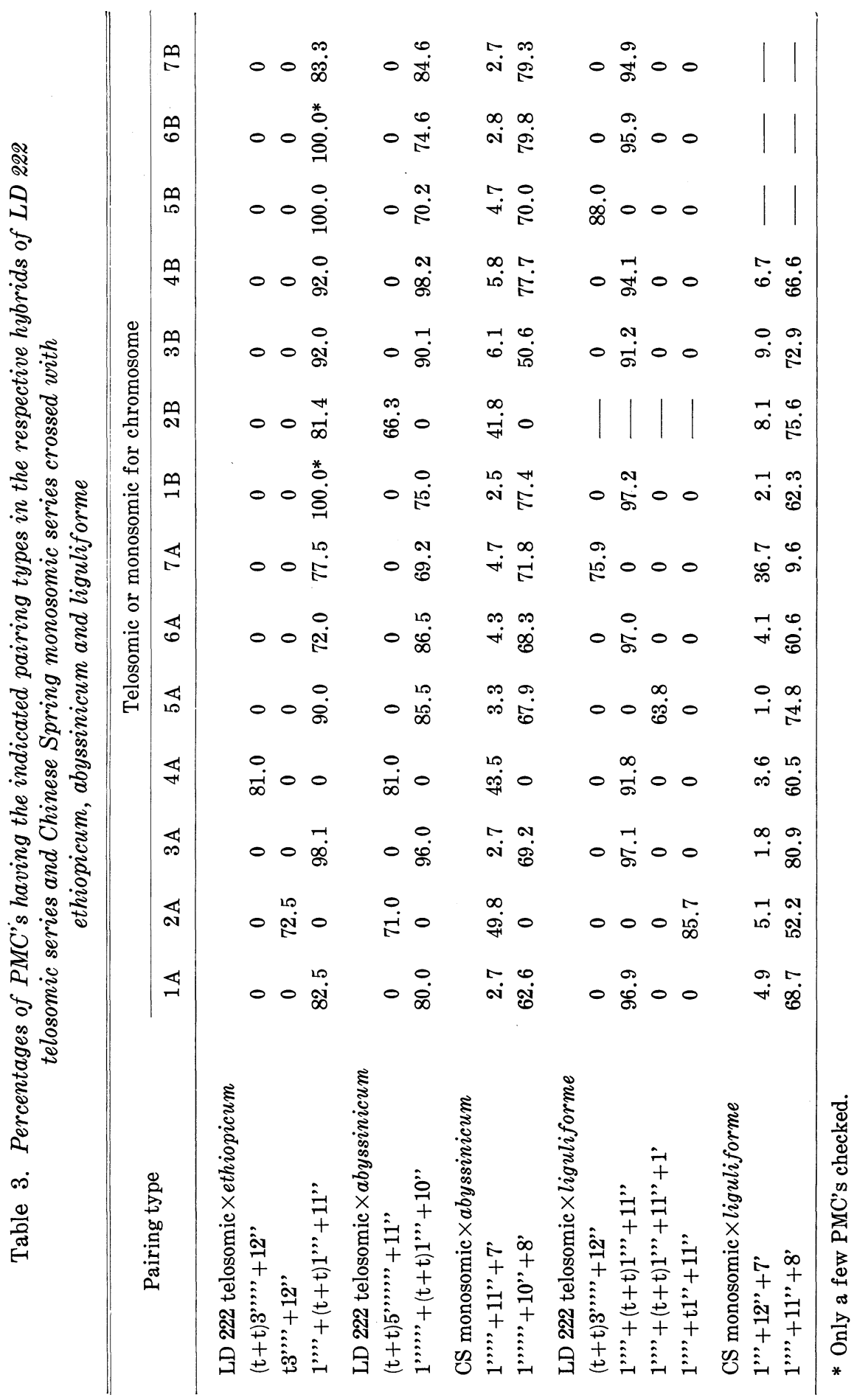


type, 1"'" $+(\mathrm{t}+\mathrm{t}) 1$ 1" +10 ", was confirmed in all but lines $2 \mathrm{~A}, 4 \mathrm{~A}$ and $2 \mathrm{~B}$. Among the variant pairing types in these lines, though not listed in Table 3, the one having one telocentric as a univalent was the most common and remarkable (ca. $21 \%)$ in line 1B. Another variant type, especially noticeable (ca. $25 \%$ ) in $7 \mathrm{~A}$, was occurrence of two univalents of complete chromosomes.

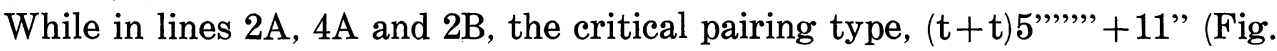
$1-D)$, was observed with the frequencies of $71.0 \%, 81.0 \%, 66.3 \%$, respectively. Most of the variant pairing types were dissociation of the telocentric marked septivalent to the component parts, which will be considered later.

In the monosomic hybrid lines, the critical pairing type, 1"'” +11 " +7 ', was confirmed, as expected, in lines $2 \mathrm{~A}, 4 \mathrm{~A}$ and $2 \mathrm{~B}$, with moderate frequencies, but rarely in the other lines which showed mostly non-critical pairing type, 1 "'," $+10 "+8$ '. In every lines, either critical and non-critical, some variant pairing types occurred with considerable frequencies; for example dissociation of a sexivalent into 1"' +1 " or 2" in non-critical lines and dissociation of a quinquevalent into 1 "' +1 ' or 1 "' +1 " in the critical lines. Consequently it is concluded without doubt that chromosomes $2 \mathrm{~A}, 4 \mathrm{~A}$ and $2 \mathrm{~B}$ are involved in the two reciprocal translocations of Abyssinicum type.

As shown in the previous paragraph, $2 \mathrm{~A}-4 \mathrm{~A}$ translocation was detected in Ethiopicum type. Accordingly, it seems reasonable to assume that Abyssinicum type translocations could result from an additional reciprocal translocation between $2 \mathrm{~A}$ and $2 \mathrm{~B}$ or between $4 \mathrm{~A}$ and $2 \mathrm{~B}$, that occurred in Ethiopicum type. The alternative hypothesis that one translocation comes from abyssinicum and the other from LD 222 can be excluded based on the pairing behavior in $\mathrm{F}_{1}$ 's listed in Table 1. In the telosomic and monosomic hybrid lines for $2 \mathrm{~A}, 4 \mathrm{~A}$ and $2 \mathrm{~B}$, a multivalent failed to remain fully associated and separated to component parts with the relative frequencies shown in Table 4. These variant pairing types would provide some clues as to which additional translocation, $2 \mathrm{~A}-2 \mathrm{~B}$ or $4 \mathrm{~A}-2 \mathrm{~B}$ could occur. Fig. 2 shows the assumed pachytene configuration in the heterozygote for Abyssinicum type translocation. There are six arms where dissociation due to desynapsis or precocious chiasma terminalization could occur (Fig. 2a-f). Generally speaking, dissociation is little likely to occur in the non-translocated arms (e and f), and probably so in the present case because of metacentric nature of all three chromosomes involved. In Table 4 it is remarkable that pairing types, $t 5$ "'"' +1 ' and $t 4$ "'” $+t 1$ "' in telosomic hybrid $2 \mathrm{~A}$ and 1 "' +1 ' in monosomic hybrid $2 \mathrm{~A}$ occurred with very low frequencies. If the above assumption of rarer dissociation at arms e and $\mathrm{f}$ were true, chromosome $2 \mathrm{~A}$ should be present at position $\mathrm{C}$. Considerably high occurrence of t3"' + t2" (Fig. 1-E) and 1"' +1 " found in both hybrid lines of $2 \mathrm{~A}$ are best explained by the assumption mentioned above. If position $\mathrm{C}$ were occupied alternatively by chromosome $4 \mathrm{~A}$, dissociation at $\mathrm{e}$ and $\mathrm{f}$ should occur with the higher frequencies and as high as at $a$ and $b$ in mono- 
Table 4. Percentages of PMC's having the indicated pairing types of the partially dissociated multivalent in the hybrids of $L D$ 222 telosomics and Chinese Spring monosomics crossed with abyssinicum

\begin{tabular}{|c|c|c|c|}
\hline \multirow{2}{*}{ Pairing type } & \multicolumn{3}{|c|}{ Telosomic or monosomic for chromosome } \\
\hline & $2 \mathrm{~A}$ & $4 \mathrm{~A}$ & $2 \mathrm{~B}$ \\
\hline \multicolumn{4}{|l|}{ Telosomic hybrid } \\
\hline t5,",'”+t' & 5.5 & 37.4 & 19.3 \\
\hline $\mathrm{t} 4$ ",'”+t1"' & 8.3 & 16.8 & 38.9 \\
\hline $\mathrm{t} 3^{\prime \prime \prime \prime}+\mathrm{t} 2, "$ & 75.2 & 33.2 & 38.6 \\
\hline others* & 11.0 & 12.6 & 3.3 \\
\hline \multicolumn{4}{|c|}{ Monosomic hybrid } \\
\hline $1, ",+1 '$ & 4.0 & 47.9 & 43.2 \\
\hline $1 ", '+1 "$ & 96.0 & 52.1 & 56.8 \\
\hline
\end{tabular}

* The types not distinguishable one from the other.

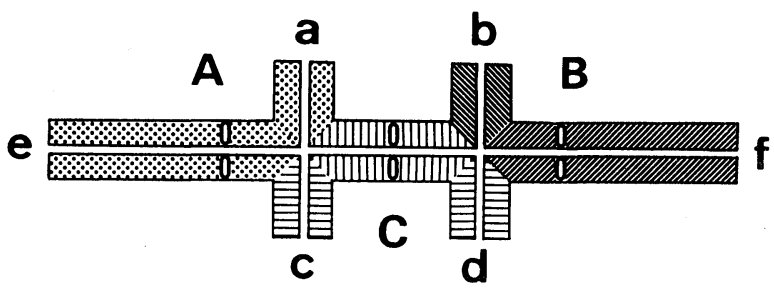

Fig. 2. Assumed pachytene configuration in the heterozygote for Abyssinicum chromosome type.

somic hybrid in particular. This is not consistent with the above assumption. Then, locating chromosomes $2 \mathrm{~A}, 4 \mathrm{~A}$ and $2 \mathrm{~B}$ at positions $\mathrm{C}, \mathrm{A}$ and $\mathrm{B}$ respectively, the higher rate of dissociation at a and/or $b$ would be estimated from the highest occurrence of $\mathrm{t} 3$ "" $+\mathrm{t} 2$ "' in telosomic hybrid $2 \mathrm{~A}$. Comparing the frequencies of $t 5$ ","' $+\mathrm{t}$ ' and $\mathrm{t} 4$ ","' $+\mathrm{t} 1$ " (Fig. 1-F) between lines $4 \mathrm{~A}$ and $2 \mathrm{~B}$ the dissociation rate at a seems to be twice as high as at $b$, which is not inconsistent with the above assumptions. Considering the frequencies of 13 "', +t2" ' in these three telosomic hybrids, the dissociation rates at $\mathrm{c}$ and $\mathrm{d}$ are roughly estimated as nearly half as those at a and b. If it is the case, however, t5""," $+t$ ' should occur with much more frequency. Therefore, though it is not valid to estimate from data now available the dissociation rate at each of six arms, three chromosomes $2 \mathrm{~A}, 4 \mathrm{~A}$ and $2 \mathrm{~B}$ can be located at position $\mathrm{C}, \mathrm{A}$ and $\mathrm{B}$ in Fig. 2, respectively. Accordingly, abyssinicum's additional reciprocal translocation that occurred in Ethiopicum chromosome type can be concluded to be between the non-translocated arm of chromosome $2 \mathrm{~A}$ and 
chromosome $2 \mathrm{~B}$.

c) Liguliforme type

As in the case of Abyssinicum type two aneuploid hybrid series, though more or less incomplete, were raised. Telosomic hybrid line $2 \mathrm{~A}$ was monotelodisomic and the others were doubletelotrisomic, with the exception of line 5A that had an unidentified extra chromosome. As evident from Table 3 , $(\mathrm{t}+\mathrm{t}) 3^{\prime \prime}, "+12$ ", a typical critical pairing type was confirmed in telosomic hybrid lines $7 \mathrm{~A}$ and $5 \mathrm{~B}$, but not found in the other lines. Dissociation of $(t+t) 3$ "'" into t2" $+t 1$ " occurred in about $20 \%$ of PMC's in line 7A. On the other hand, non-critical pairing type occurred in the other lines with high frequencies. The most common variant type of pairing was such that the telocentric failed to associate and occurred as a univalent in those lines. The critical pairing type, 1" +12 " +7 ', was detected more or less in all the monosomic hybrid lines checked, but with the highest frequency in line 7A. Then, $7 \mathrm{~A}$ seems to be involved in this type of translocation. However, one of noncritical pairing types, 13" +8 ', was found in about $40 \%$ of PMC's even in 7A, but it is considered to be the result from dissociation of the trivalent into bivalent and univalent. 1 "," +11 " +8 , non-critical pairing type was found again in all the lines checked, but with the lowest frequency in line 7A. As evident in the foregoing section, Liguliforme type translocation involves chromosome $5 \mathrm{~B}$ as a partner, and all the evidences so far available indicate that chromosomes $7 \mathrm{~A}$ and $5 \mathrm{~B}$ are involved in Liguliforme type translocation. One of the features of pairing type in those hybrids involving either liguliforme and aureum is that two quadrivalents occurred simultaneously in some $20 \%$ or $30 \%$ of PMC's. Based on data from Chinese Spring-liguliforme hybrid it is estimated that the quadrivalent composed of $7 \mathrm{~A}-5 \mathrm{~B}$ translocation occurs alone in about $80 \%$ of PMC's and the rare quadrivalent of unknown chromosomes alone in a few percent of them. It should be noticed that the pairing type, 1"" +1 " +10 " +7 ', that might be a critical pairing type was found in $29.6 \%$ of PMC's in line $2 \mathrm{~A}$. Then, the assumption that a rare quadrivalent involves chromosome $2 \mathrm{~A}$ as one of the partners may not be excluded.

\section{DISCUSSION}

In the present study, varieties and cultivars of cultivated Emmer wheat could be grouped into four chromosome types according to the reciprocal translocations detected at MI as a ring or a chain of multivalent. Besides LD 222 type that is considered as a standard type, identifying Ethiopicum type as $2 \mathrm{~A}-4 \mathrm{~A}$ reciprocal translocation, Abyssinicum type as $4 \mathrm{~A}-2 \mathrm{~A}: 2 \mathrm{~A}-2 \mathrm{~B}$ and Liguliforme type as $7 \mathrm{~A}-5 \mathrm{~B}$ is consistent with the pairing behavior observed in the intergroup hybrids represented in Table 1. Kawahara (1984) presented in his doctor thesis the review of papers that reported translocations in Triticum and Aegilops. In tetraploid wheat only one that reported by Dalal and 
Sadanaga (1965) showed chromosomes involved, i.e. carthlicum had a reciprocal translocation between $2 \mathrm{~A}(\mathrm{II})$ and $3 \mathrm{~A}$. Kawahara himself identified five translocations in wild Emmer, and showed the genomes to which the translocated chromosomes belong; three were between chromosomes of genome B, one between those of genome $\mathrm{A}$ and another between those of genome $\mathrm{A}$ and B. According to Kawahara's summarization, chromosomes of genome B were involved most of ten in reciprocal translocations in hexaploid wheat, $7 \mathrm{~B}$ being the highest in the whole and $4 \mathrm{~A}$ the highest among chromosomes of genome A. In cultivated form of Emmer wheat, chromosomes 2A, 3A, 4A, 7A, 2B and $5 \mathrm{~B}$ were so far proved to be involved in four different translocations, only $2 \mathrm{~A}$ in three cases. Therefore, A genome chromosomes were involved six times and B genome ones two times in cultivated form of Emmer wheat, that is rather in contrast to hexaploid wheat. However, chromosome identification of Kawahara's six chromosome types still remaines to be worked out before further considerations.

\section{REFERENCES}

Burnham, C. R. (1956) Chromosomal interchanges in plants. Bot. Rev. 22, 419-552.

Dalal, K. C. and SAdAnaGa, K. (1965) Identification of chromosomes involved in translocation in $\mathrm{F}_{1}$ hybrid of two species of tetraploid wheat. Can. J. Genet. Cytol. 7, 88-96.

Hosono, S. (1935) Karyologische Studien bei reinen Arten und Bastarden der Emmerreihe. I. Reifungsteilungen. Jpn. J. Bot. 7, 301-321.

KawAHARA, T. (1984) Studies on intraspecific structural differentiation of chromosomes in wild tetraploid wheats. Dr. Thesis submit. Kyoto Univ.: 1-250.

KaWAhara, T. and TANAKA, M. (1978) Identification of reciprocal translocation chromosome types in Emmer wheats. I. Triticum dicoccoides KöRN. WIS 45, 46, 29-31.

LiNDE-LAURSEN, I. and LARSEN, J. (1974) The use of doublemonotelodisomics to identify translocations in Triticum aestivum. Hereditas 78, 245-250.

Nishikawa, K. (1962) Reciprocal translocations in Emmer wheat. Ann. Rep. Nat. Inst. Genet. 13, 50 .

NishiKaWA, K. (1967) Introduction of telocentric chromosomes of Chinese Spring into Triticum durum. Wheat Inf. Serv. 25, 5-6.

Schmidt, J. W. and Johnson, V. A. (1963) A sphaerococcum like tetraploid wheat. Crop. Sci. 3, 98-99.

Sмiтн, L. (1947) Irregularities in a hybrid between T. durum and T. persicum. J. Agr. Res. 75, 301-305.

Tsunewaki, K. (1963) An Emmer wheat with 15 chromosome pairs. Can. J. Genet. Cytol. 5, $462-466$.

YAMASHITA, K. (1950) A synthetic complex heterozygote in Einkorn wheat; aegilopoides and monococcum. Proc. Japan Acad. 26, 66-71. 